\title{
A Kinetic Study of Manganese Leaching from Low-Grade Psilomelane Ore by Acetic-Tannic Acid Lixiviant
}

\author{
Widya Aryani ${ }^{1}$ \\ Astria Gesta Anggraini ${ }^{1}$ \\ Fathan Bahfie ${ }^{1}$ \\ Ulin Herlina ${ }^{1}$ \\ Muhammad Al Muttaqii ${ }^{2}$ \\ Erik Prasetyo ${ }^{1,3 *}$
}

\author{
${ }^{1}$ Research Unit for Mineral Technology, National Research and Innovation Agency \\ ${ }^{2}$ Research Center for Chemistry, National Research and Innovation Agency \\ ${ }^{3}$ Department of Chemical Engineering, Norwegian University of Science and Technology \\ *e-mail: erik.prasetyo@lipi.go.id
}

Submitted 23 February 2021

Revised 08 October 2021

Accepted 23 November 2021

\begin{abstract}
Kinetic leaching of psilomelane using tannic acid as reductant and acetic acid as an acidic modifier is investigated in terms of tannic acid and acetic acid concentration, solid-liquid ratio, particle size and temperature. Kinetic modelling using three models: shrinking core, shrinking particle, and diffusion-interface transfer model revealed that at room temperature leaching $\left(30^{\circ} \mathrm{C}\right)$, experimental data are best modelled using diffusion-interface transfer model, indicating the dissolution of $\mathrm{Mn}$ is more affected by reaction rate among reactants and their concentration in bulk volume rather than by transfer across the boundary layer. At higher temperatures $\left(\geq 50^{\circ} \mathrm{C}\right)$, the shrinking particle model fits the experimental data best, suggesting the prominence of the diffusion process boundary layer. The apparent activation energy obtained at two temperatures were 13.1 and $52.7 \mathrm{~kJ} / \mathrm{mol}$ for lower and higher temperatures. Plot between rate constant and concentration yields reaction order to be 1.28 for tannic acid and 0.73 for acetic acid. A semiempirical model for each temperature range is proposed to describe the overall manganese leaching efficiency.
\end{abstract}

Keywords: Reductive leaching, manganese, psilomelane, tannic acid, acetic acid, kinetic

\section{INTRODUCTION}

Manganese $(\mathrm{Mn})$ possesses wide application in many fields, which the steel industry will consume the majority (about 80 $90 \%)$, while the rest will be available as chemicals, e.g. fertilizers, battery and electronic components (Corathers, 2015; Zhang et al., 2015; Zheng et al., 2020). Generally, the pyrometallurgical process requires high-grade manganese ore to satisfy the ferromanganese steel industry. It encouraged selective mining practice, leaving low grade and sub-economic ore. These ore categories inspired novel processes, especially chemical methods, i.e. leaching, to effectively use the lean resources and minimize mine wastes (Lin et al., 2016; Andini et al., 2021). Most of the manganese ore available was dominated by manganese 
dioxide, i.e. pyrolusite. In contrast, other types of ore, such as rhodochrosite and psilomelane, have received less attention than manganese dioxide.

Psilomelane is a barium manganese oxide hydroxide, which in this case, the valence of manganese in the crystal structure is either +2 or +4 . Since the reaction consumes protons, most manganese leaching procedures involved the reduction of insoluble $\mathrm{Mn}(\mathrm{IV})$ to soluble $\mathrm{Mn}$ (II) in acidic conditions. Numerous reductants have been proposed so far, including inorganic reductant, e.g. hydrogen peroxide (Buzatu et al., 2014), SO2 gas (Deng et al., 2019) and organic reductant, e.g. glucose (Biswas et al., 2016), ascorbic acid (Sinha et al., 2020), oxalic acid (Azizi et al., 2012; El Hazek and Gabr, 2016), methanol (Momade and Momade, 1999), lignin (Xiong et al., 2018) and formic acid (Lu et al., 2015). A previous report in $\mathrm{MnO}_{2}$ reduction using tannic acid in sulfuric acid media as a green and economical alternative lixiviant for manganese leaching revealed that the $\mathrm{Mn}$ leaching selectivity over iron could be achieved by controlling initial leaching conditions (tannic acid concentration, sulfuric acid concentration and temperature) (Prasetyo et al., 2019). This research will test tannic acid efficacy to reduce and dissolve manganese from psilomelane ore. However, in this case, sulfuric acid could not be used due to the barium content in the ore. It is hypothesized that the presence of sulfate in media will hinder the dissolution of barium in psilomelane and form the barium sulfate precipitate. Hence the sulfuric acid as a proton source in this research will be replaced by acetic acid. The synergy between tannic acid and acetic acid will be tested in this research in terms of manganese leaching efficiency, which will be stressed on its kinetic aspect to discern possible leaching mechanisms. The relationship between kinetic parameters (leaching time) and other leaching parameters such as tannic acid concentration, acetic acid concentration, temperature, the grain size will be evaluated and used to determine the kinetic model. Moreover, it described the leaching process supported by characterization results by $\mathrm{X}$ Ray Diffraction, X-Ray Fluorescence, and SEM-EDS data. Aside from Mn, the behaviour of another element ( $\mathrm{Fe}$ ) during leaching will be investigated and discussed.

\section{MATERIAL AND METHOD}

Manganese ore was kindly donated by PT Gemala Borneo Utama from Maluku mine site, Indonesia. The ore sample was manually crushed, ball-milled and sieved into several fraction sizes. Chemicals such as tannic acid, acetic acid glacial, hydrochloric acid and nitric acid were obtained from Merck Chemical, Darmstadt, Germany. X-ray diffraction (Panalytical, Expert3 Powder) revealed the major phase (Fig. 1) to be hollandite $\left(\mathrm{Ba}_{1.252} \mathrm{Mn}_{8} \mathrm{O}_{16}\right)$ and silica $\left(\mathrm{SiO}_{2}\right)$. X-Ray Fluorescence (Panalytical X'Pert 3 Powder) was carried out to determine major elements presented in the ore (Table 1). Element content in the ore sample was also determined using ICP-OES (Analytik Jena, Plasma Quant 9000 Elite, Germany) after digestion using a mixture of concentrated hydrochloric and nitric acid (3:1), which results were listed in Table 2.

Leaching experiments were carried out using the batch method by mixing $20 \mathrm{~mL}$ lixiviant containing tannic acid-acetic acid mixture, pre-heated in sealed $200 \mathrm{~mL}$ conical flask in incubator orbital shaker. 
190 A Kinetic Study of Manganese Leaching from Low-Grade Psilomelane Ore by Acetic-tannic Acid Lixiviant

Table 1. Major Components of Manganese Ore based on X-ray Fluorescence Characterization

\begin{tabular}{lllllllll}
\hline Components & $\mathbf{A l}_{2} \mathbf{O}_{3}$ & $\mathbf{S i O}_{2}$ & $\mathbf{K}_{\mathbf{2}} \mathbf{O}$ & $\mathbf{C a O}$ & $\mathbf{M n O}$ & $\mathbf{F e}_{2} \mathbf{O}_{3}$ & $\mathbf{B a O}$ & $\mathbf{P b O}$ \\
\hline Content (\%) & 2.15 & 6.02 & 2.69 & 1.47 & 59.18 & 8.97 & 3.52 & 1.9 \\
\hline
\end{tabular}

Table 2. Distribution of Element Content in Mn Ore (in \%) In Each Fraction Size Based on Aqua Regia Digestion and ICP-OES Determination

\begin{tabular}{lllllll}
\hline Components & Mn & Ba & Al & Ca & Mg & Fe \\
\hline Content (\%) & $34.2 \pm 0.8$ & $1.93 \pm 0.03$ & $0.87 \pm 0.14$ & $1.25 \pm 0.82$ & $0.21 \pm 0.05$ & $4.10 \pm 0.33$ \\
\hline
\end{tabular}

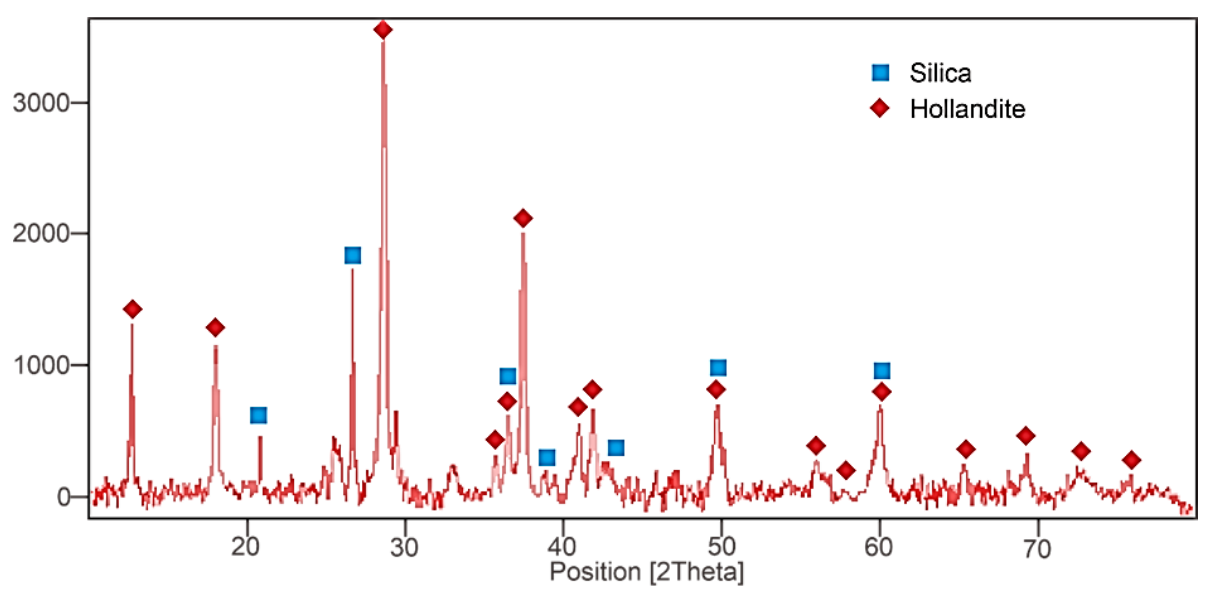

Fig 1. Mineral Phases in Mn Ore: Silica $\left(\mathrm{SiO}_{2}\right)$ and Hollandite $\left(\mathrm{Ba}_{1.252} \mathrm{Mn}_{8} \mathrm{O}_{16}\right)$

After the heated lixiviant temperature reached the desired one, $\mathrm{Mn}$ ore powder was introduced into the conical flask, and the mixture was agitated at $200 \mathrm{rpm}$. After the leaching was completed, the filtrate was separated from solid residue using centrifugation (4500 rpm, $10 \mathrm{~min}$ ) and filtration using Whatman 42 paper. The filtrate was then diluted using nitric acid, and element contents were determined using ICP-OES. Leaching efficiency $(R, \%)$ was calculated using a mass balance (Eq. 1).

$R=\frac{C_{E} \times V}{C_{o} \times m} \times 100 \%$

where:
$C_{E}$ metal concentration in pregnant leach solution $(\mathrm{mg} / \mathrm{L})$

$C_{0}$ metal content in $\mathrm{Mn}$ ore $(\mathrm{mg} / \mathrm{g}$ )

$M \quad$ mass of $\mathrm{Mn}$ ore used in leaching (g)

$V \quad$ lixiviant volume $(\mathrm{L})$

\section{RESULTS AND DISCUSSION}

\section{Effect of Tannic Acid Concentration}

The effect of tannic acid was studied at 25, 50 and $100 \mathrm{~g} / \mathrm{L}$ concentrations. Constant variables in this study were acetic acid concentration $2 \mathrm{M}$, temperature $30{ }^{\circ} \mathrm{C}$, pulp density $50 \mathrm{~g} / \mathrm{L}$, particle size less than 53 microns. Fig. $2 a$ showed a positive 
correlation between tannic acid concentration and $\mathrm{Mn}$ leaching rate. However, the tannic acid concentration 25, 50 and $100 \mathrm{~g} / \mathrm{L}$ exceeded the stoichiometric value $(3 \mathrm{~g} / \mathrm{L})$. Although the tannic acid concentration far exceeded the stoichiometric value, the recovery of $\mathrm{Mn}$ did not attain the maximum value. In the case of $25 \mathrm{~g} / \mathrm{L}$ tannic acid concentration, the saturation value of $\mathrm{Mn}$ recovery value was about $40 \%$, while for 50 and $100 \mathrm{~g} / \mathrm{L}$ tannic acid concentration, the saturation values were 50 and $70 \%$. It indicated the reaction interface was more influenced by the reaction rate of $\mathrm{MnO}_{2}$ with tannic acid than by mass transfer across the boundary layer (Al-Anber et al., 2020). In the case of Fe, leaching efficiency (Fig. 2b) generally increased within 120 min leaching, then the efficiency decreased. Based on previous research (Prasetyo et al., 2019), solution $\mathrm{pH}$ increased during leaching since proton was consumed during manganese reduction. The drop of proton concentration in bulk volume increased the $\mathrm{pH}$ (Fig. $2 \mathrm{c}$ ) and triggered the precipitation of Fe.

\section{Effect of Acetic Acid Concentration}

Fig. 3a demonstrates the relationship between acetic acid concentration the manganese recovery. Constant variables include tannic acid concentration $50 \mathrm{~g} / \mathrm{L}$, pulp density $50 \mathrm{~g} / \mathrm{L}$, temperature $30{ }^{\circ} \mathrm{C}$, particle size less than 53 microns.

Increasing acetic acid concentration improved the leaching efficiency of $\mathrm{Mn}$. There is no significant improvement of $\mathrm{Mn}$ recovery from acetic acid concentration $2 \mathrm{M}$ to $5 \mathrm{M}$. Considering the $\mathrm{pK}_{\mathrm{a}}$ value for acetic acid, which is 4.756 , the total proton concentration generated by $0.5,1,2$ and $5 \mathrm{M}$ are $3.0,4.2,5.9$ and $9.3 \mathrm{mM}$, respectively.
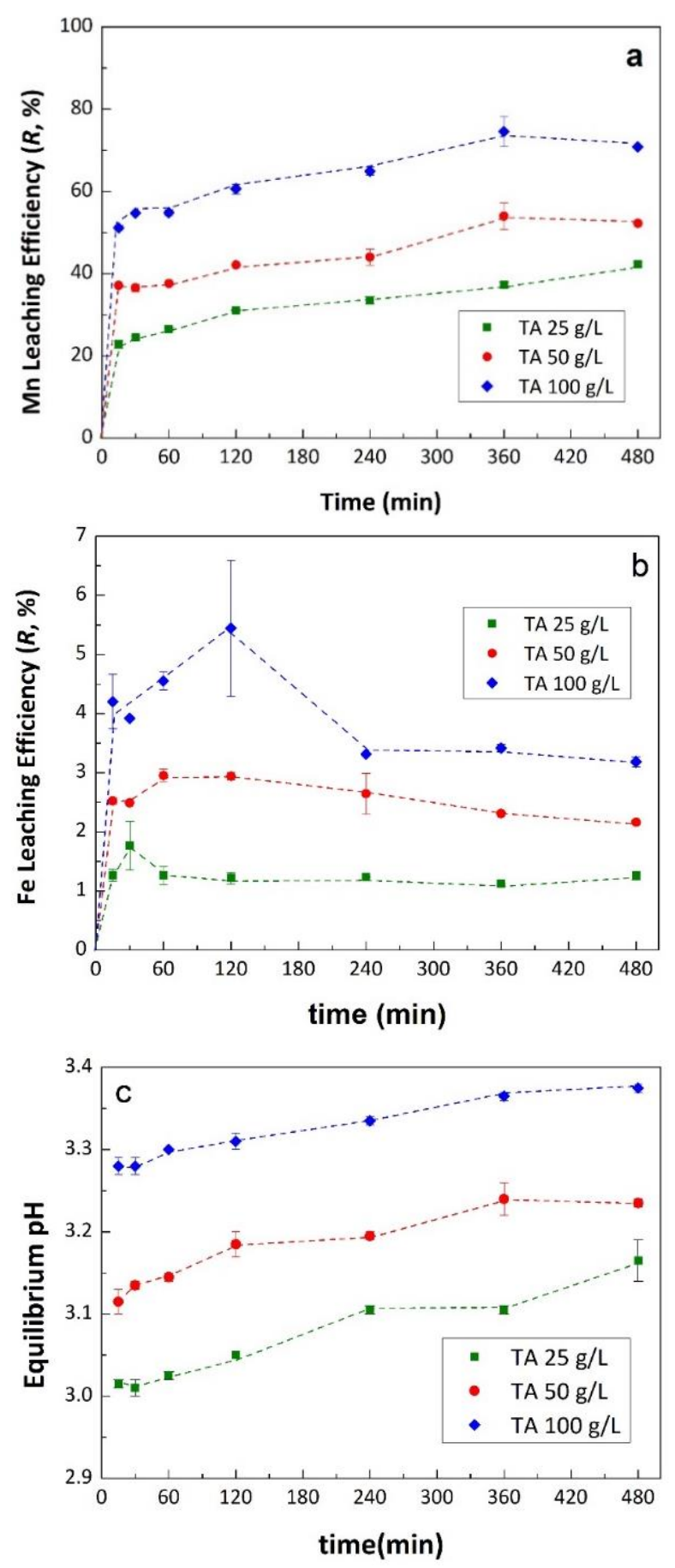

Fig 2. a. Mn Leaching Efficiency, b. Fe Leaching Efficiency and c. Pregnant Leach Solution $\mathrm{pH}$ as A Function of Leaching Time at Various Tannic Acid Concentrations.

This amount is far below the stoichiometric value for total Mn dissolution. Acetic acid $5 \mathrm{M}$ only could provide $3 \%$ of the proton required for complete $\mathrm{Mn}$ 
192 A Kinetic Study of Manganese Leaching from Low-Grade Psilomelane Ore by Acetic-tannic Acid Lixiviant

dissolution. However, the maximum $\mathrm{Mn}$ recovery could reach $50 \%$ at $2 \mathrm{M}$ and $5 \mathrm{M}$ acetic acid.

Considering the function of acetic acid, which is initially assumed as a proton donor in the reaction, the acetic acid alone clearly could not provide sufficient proton for manganese reduction. However, during tannic acid oxidation, the proton is also produced (Eq. 2, Trojanowicz et al., 2018). The proton will hypothetically sustain the reductive leaching of manganese ore (psilomelane), according to Eq. 3.

$$
\begin{aligned}
& \mathrm{C}_{55} \mathrm{H}_{40} \mathrm{O}_{54}+56 \mathrm{H}_{2} \mathrm{O} \\
& \rightarrow 55 \mathrm{CO}_{2}+152 \mathrm{H}^{+}+152 e^{-} \\
& \mathrm{BaMn}^{2+} \mathrm{Mn}^{4+}{ }_{8} \mathrm{O}_{16}\left(\mathrm{OH}_{4}+36 \mathrm{H}^{+}+16 e^{-}\right. \\
& \rightarrow \mathrm{Ba}^{2+}+9 \mathrm{Mn}^{2+}+20 \mathrm{H}_{2}
\end{aligned}
$$

Combining Eq. 2 and 3:

$$
\begin{aligned}
2 \mathrm{C}_{55} \mathrm{H}_{40} \mathrm{O}_{54}+ & 19 \mathrm{BaMn}^{2+} \mathrm{Mn}^{4+}{ }_{8} \mathrm{O}_{16}(\mathrm{OH})_{4} \\
+380 \mathrm{H}^{+} \rightarrow & 110 \mathrm{CO}_{2}+19 \mathrm{Ba}^{2+}+171 \mathrm{Mn}^{2+} \\
+ & +268 \mathrm{H}_{2} \mathrm{O}
\end{aligned}
$$

During leaching, slightly increasing $\mathrm{pH}$ indicates that the proton consumed during redox reaction was sustained mainly by tannic acid degradation. Acetic acid maintained the acidic condition to ensure the reaction proceeded, especially at the initial reaction stage. Since tannic acid oxidation, which also generated proton, occurred on the surface boundary, the reaction interface was hypothesised to be more prominent than mass transfer in terms of acidity (proton concentration) to the manganese dissolution.

In the case of iron leaching efficiency, increasing acetic acid concentration also improved iron concentration in the leaching solution (Fig. 3b). Since higher acetic acid concentration increased equilibrium pH (Fig. 3c), Fe precipitation as hydroxides was prevented.

\section{Effect of Particle Size}
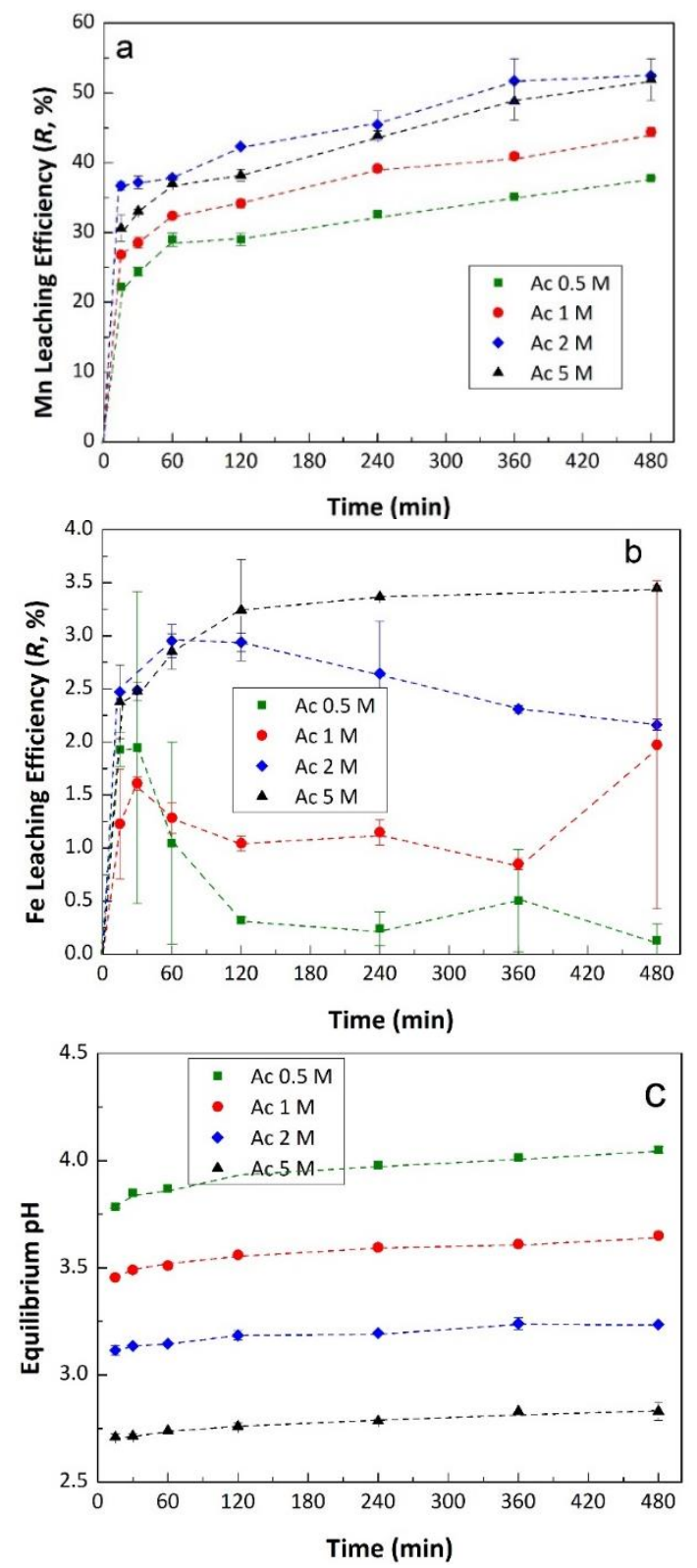

Fig 3. a. Mn Leaching Efficiency, b. Fe Leaching Efficiency and c. Pregnant Leach Solution $\mathrm{pH}$ as A Function of Leaching Time at Various Acetic Acid Concentrations.

Based on the results shown in Fig. 4, there is no significant change of leaching rate of $\mathrm{Mn}$ for any fraction sizes larger than 53 microns, which maximum leaching 
efficiency converges to $30 \%$. Hence it was hard to discern the effect of particle size on $\mathrm{Mn}$ recovery. For fraction size less than 53 microns, the efficiency drastically increases to about $52 \%$.

Although the milling improved $\mathrm{Mn}$ extraction, other factors such as energy required (economical) reason have to be considered. The offset of particle size on 53 microns is considered reasonable, compared to other literature surveys (Xue et al., 2016; Sun et al., 2018). Therefore this particle size fraction is used in further kinetic studies.

\section{Effect of Solid-Liquid Ratio}

Effect of solid-liquid ratio was studied at 33,50 , and $100 \mathrm{~g} / \mathrm{L}$ with constant variables include tannic acid concentration $50 \mathrm{~g} / \mathrm{L}$, acetic acid $2 \mathrm{M}$, particle size less than 53 microns, temperature $30^{\circ} \mathrm{C}$. The results in Fig. 5 demonstrate that the recovery of $\mathrm{Mn}$, as expected, doubled when pulp density decreased from $100 \mathrm{~g} / \mathrm{L}$ to $50 \mathrm{~g} / \mathrm{L}$. However, when further pulp density decrease to $33 \mathrm{~g} / \mathrm{L}$ does not significantly affect the Mn leaching efficiency.

\section{Effect of Temperature}

Fig. 6a illustrates the effect of temperature on $\mathrm{Mn}$ leaching efficiency at 30, 50 and $80{ }^{\circ} \mathrm{C}$, at constant condition solidliquid ratio $50 \mathrm{~g} / \mathrm{L}$, tannic acid $50 \mathrm{~g} / \mathrm{L}$, acetic acid $2 \mathrm{M}$ and particle size less than 53 microns.

The results show that the change of leaching efficiency was not significant when the leaching temperature increased from 30 and $50{ }^{\circ} \mathrm{C}$, which maximum recovery was $50 \%$ attained within $6 \mathrm{~h}$ leaching. Increasing temperature to $80^{\circ} \mathrm{C}$ improved the leaching efficiency to $77 \%$ within $8 \mathrm{~h}$.
Since it was postulated that increasing temperature would cause intense movement of solute in the liquid phase, at a lower temperature $\left(<50{ }^{\circ} \mathrm{C}\right)$, the intense movement was only applied in bulk volume (mass transfer to the boundary layer).

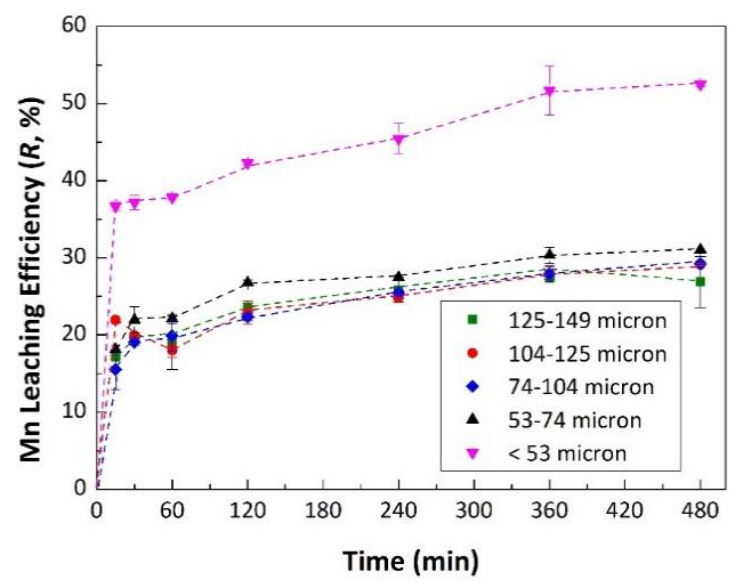

Fig 4. Mn Leaching Efficiency as A Function of Leaching Time at Various Particle Sizes

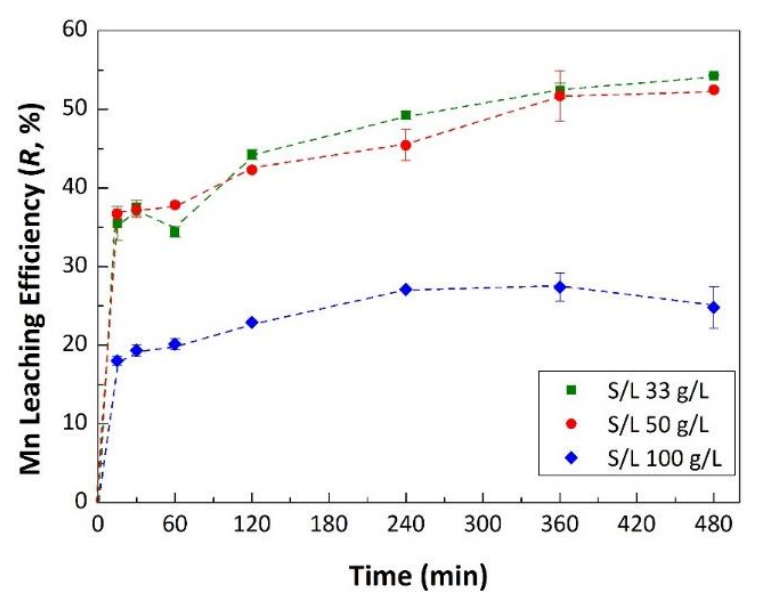

Fig 5. Mn Leaching Efficiency as A Function of Leaching Time at Various Solid-Liquid Ratios.

In contrast, higher energy input $\left(>50^{\circ} \mathrm{C}\right)$ boosted movement in the bulk volume and drove the movement through diffusion and interface zone (the pores and reacted layer of associate mineral particle). Hence the increase of $\mathrm{Mn}$ recovery is substantial at $80{ }^{\circ} \mathrm{C}$. In the case of $\mathrm{Fe}$, the increasing temperature decreased the dissolution (Fig. 
194 A Kinetic Study of Manganese Leaching from Low-Grade Psilomelane Ore by Acetic-tannic Acid Lixiviant

$6 b)$, which is probably caused by iron's tendency to precipitate at higher temperatures as magnetite or goethite (Pagnanelli et al., 2004).
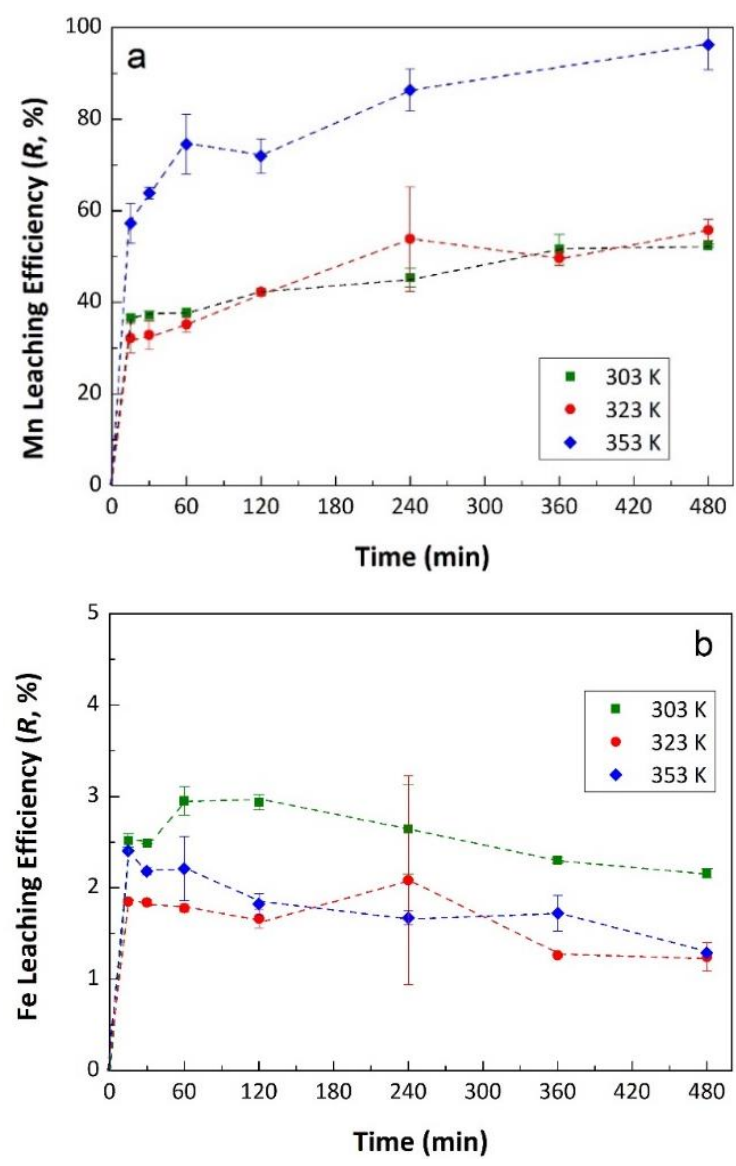

Fig 6. a. Mn, b. Fe Leaching Efficiency as A

Function of Leaching Time at Various

Leaching Temperatures.

\section{Leaching Kinetics}

Several models will be applied, including the shrinking core model (SCM), shrinking particle model (SPM) and diffusion-interface transfer to describe the kinetic process as suggested by Dickinson and Heal (1999). SCM (Eq. 5), proposed by Levenspiel (Levenspiel, 1999), was generally used to explain most of the mineral leaching process, which controlling rate depends on several steps, and one of the shrinking core models is controlled by chemical reaction (Eq. 1).
In the case of SPM (Eq. 6), the dissolution process is assumed to be controlled by diffusion through the inner layer (Xue et al., 2016). Aside from controlling rate and dissolution rate assumption in SCM, the other model diffusion-interface transfer models (Eq. 7) is proposed by Dickinson and Heal (1999) (Dickinson and Heal, 1999). This model has been successfully applied to many leaching processes, including $\mathrm{Zn}$ and $\mathrm{Cu}$ from electric arc furnace dust using amino acid (Prasetyo et al., 2020), tin and lead from the printed circuit board (Moosakazemi et al., 2019) and lithium from spodumene using sulfuric-hydrofluoric acid (Guo et al., 2019), since the model assumes the change of reactant concentration in the liquid phase.

$k_{1} t=1-(1-x)^{1 / 3}$

$k_{2} t=1-\frac{2}{3} x-(1-x)^{2 / 3}$

$k_{3} t=\frac{1}{3} \ln (1-x)-[1-(1-x)]^{-1 / 3}$

where $x$ is the fraction of $M n$ leached ( $M n$ leaching efficiency in Fig 2-6), $t$ is reaction time, while $k_{1}, k_{2}$ and $k_{3}$ are rate constants.

The Arrhenius equation defines the relationship between temperature and reaction rate constant (Eq. 8), where $A, T$ and $R$ are frequency factors, temperature and gas constant, respectively. The $k$ value obtained from the regression of $k t$ and $1 / T$ is used for activation energy (Ea) calculation.

$k=A e^{-\frac{E_{a}}{R T}}$ or $\ln k=\ln A-\frac{E_{a}}{R T}$

Table 3 showed the fitting parameter of each leaching variable using three models shrinking core model (SCM), shrinking particle model (SPM), and diffusion-interface transfer (DIT). Which parameters evaluated 
include rate constant $(k)$ and coefficient correlation $\left(R^{2}\right)$. The fitting was carried out by plotting the experimental data on the $t-k t$ graph, where $t$ was leaching time and kt was calculated based on Eq. 5-7. The plot should form a linear graph, and Pearson correlation $\left(R^{2}\right)$ value was used to determine the applicability of the kinetic model to experimental data (Table 3). Generally, at room temperature $\left(30{ }^{\circ} \mathrm{C}\right)$ leaching conditions, experimental data for four variables tested (tannic acid concentration, acetic acid concentration, grain size and solid-liquid ratio) are best modelled using the diffusion-interface transfer (DIT) model. These results comply with the hypotheses discussed in previous sub-chapters regarding the effect of each variable on the kinetic Mn dissolution, in which the reaction on the solid-liquid interface is more affected by reaction rate among reactants (manganese oxide, tannic acid and acetic acid) and their concentration in bulk volume rather than by transfer across the boundary layer.

Table 3. The Value of The Rate Constant $k$ and Coefficient Correlation $\left(R^{2}\right)$ was Obtained From Experimental Data Fitting Using Shrinking Core Model (SCM), Shrinking Particle Model (SPM) and Diffusion-Interface Transfer Model (DIT)

\begin{tabular}{|c|c|c|c|c|c|c|}
\hline \multirow[b]{2}{*}{ Variables } & \multicolumn{3}{|c|}{$k$} & \multicolumn{3}{|c|}{$R^{2}$} \\
\hline & SCM & SPM & DIT & SCM & SPM & DIT \\
\hline \multicolumn{7}{|c|}{ Tannic acid concentration (g/L) } \\
\hline 25 & $1.63 \times 10^{-4}$ & $1.10 \times 10^{-4}$ & $2.68 \times 10^{-5}$ & 0.971 & 0.980 & 0.980 \\
\hline 50 & $1.81 \times 10^{-4}$ & $1.64 \times 10^{-4}$ & $4.95 \times 10^{-5}$ & 0.967 & 0.971 & 0.971 \\
\hline 100 & $2.82 \times 10^{-4}$ & $3.46 \times 10^{-4}$ & $1.59 \times 10^{-4}$ & 0.913 & 0.921 & 0.929 \\
\hline \multicolumn{7}{|c|}{ Acetic acid concentration (M) } \\
\hline 0.5 & $1.25 \times 10^{-4}$ & $7.98 \times 10^{-5}$ & $1.88 \times 10^{-5}$ & 0.914 & 0.946 & 0.958 \\
\hline 1 & $1.57 \times 10^{-4}$ & $1.17 \times 10^{-4}$ & $3.01 \times 10^{-5}$ & 0.945 & 0.968 & 0.978 \\
\hline 2 & $2.08 \times 10^{-4}$ & $1.78 \times 10^{-4}$ & $5.14 \times 10^{-5}$ & 0.974 & 0.988 & 0.993 \\
\hline 5 & $1.81 \times 10^{-4}$ & $1.64 \times 10^{-4}$ & $4.95 \times 10^{-5}$ & 0.967 & 0.971 & 0.971 \\
\hline \multicolumn{7}{|c|}{ Grain size (micron) } \\
\hline $114.5-137$ & $8.27 \times 10^{-5}$ & $3.99 \times 10^{-5}$ & $8.24 \times 10^{-6}$ & 0.819 & 0.841 & 0.849 \\
\hline $89-114.5$ & $9.70 \times 10^{-5}$ & $4.94 \times 10^{-5}$ & $1.04 \times 10^{-5}$ & 0.909 & 0.940 & 0.950 \\
\hline $63.5-89$ & $1.05 \times 10^{-5}$ & $5.18 \times 10^{-5}$ & $1.08 \times 10^{-5}$ & 0.921 & 0.957 & 0.967 \\
\hline $53-63.5$ & $9.84 \times 10^{-5}$ & $5.29 \times 10^{-5}$ & $1.14 \times 10^{-5}$ & 0.849 & 0.887 & 0.901 \\
\hline$<53$ & $2.08 \times 10^{-4}$ & $1.78 \times 10^{-4}$ & $5.14 \times 10^{-5}$ & 0.974 & 0.988 & 0.993 \\
\hline \multicolumn{7}{|c|}{$\mathrm{S} / \mathrm{L}$ rasio $(\mathrm{g} / \mathrm{L})$} \\
\hline 33 & $6.70 \times 10^{-5}$ & $3.22 \times 10^{-5}$ & $6.63 \times 10^{-6}$ & 0.659 & 0.646 & 0.639 \\
\hline 50 & $1.81 \times 10^{-4}$ & $1.64 \times 10^{-4}$ & $4.95 \times 10^{-5}$ & 0.967 & 0.971 & 0.971 \\
\hline 100 & $2.15 \times 10^{-4}$ & $1.96 \times 10^{-4}$ & $5.97 \times 10^{-5}$ & 0.911 & 0.935 & 0.953 \\
\hline \multicolumn{7}{|c|}{ Temperature $\left({ }^{\circ} \mathrm{C}\right)$} \\
\hline 30 & $1.81 \times 10^{-4}$ & $1.64 \times 10^{-4}$ & $4.95 \times 10^{-5}$ & 0.967 & 0.971 & 0.971 \\
\hline 50 & $2.53 \times 10^{-4}$ & $2.27 \times 10^{-4}$ & $6.86 \times 10^{-5}$ & 0.851 & 0.854 & 0.853 \\
\hline 80 & $8.45 \times 10^{-4}$ & $1.20 \times 10^{-3}$ & $1.78 \times 10^{-3}$ & 0.964 & 0.970 & 0.941 \\
\hline
\end{tabular}


196 A Kinetic Study of Manganese Leaching from Low-Grade Psilomelane Ore by Acetic-tannic Acid Lixiviant

In the case of temperature variables, the shrinking particle model (SPM) fits the experimental data best compared to SCM and DIT at higher temperatures $\left(\geq 50{ }^{\circ} \mathrm{C}\right.$ ), indicating the diffusion through the boundary layer is prominent. It confirmed the previous hypotheses in the sub-chapter effect of temperature. Higher energy input causes higher kinetic energy at the higher temperature and encourages particle movement (diffusion) into the inner particle layer. The previous report on $\mathrm{MnO}_{2}$ shows that increasing temperature shifts the leaching mechanism from chemical reaction control to diffusion process control, which was supported by SEM analysis (Prasetyo et al., 2019).
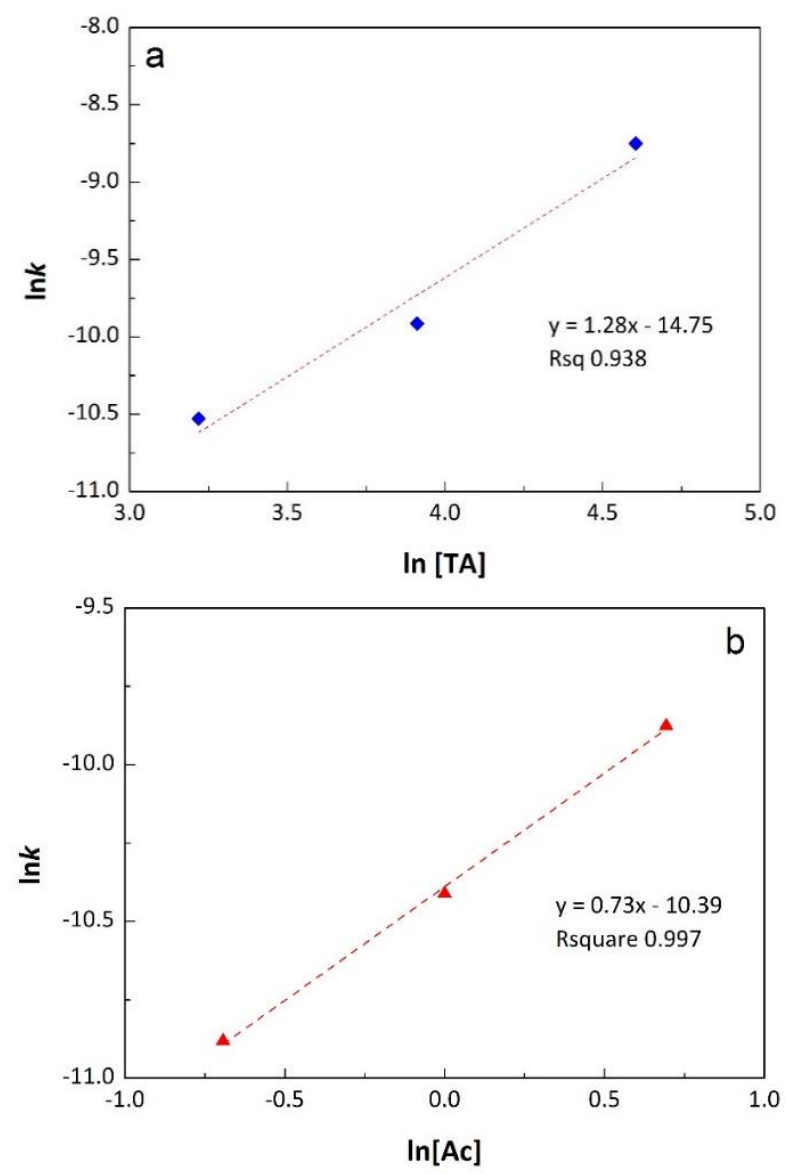

Fig 7. Plot between $\ln k$ and $\ln$

Concentration to Determine Reaction Order of a. Tannic Acid b. Acetic Acid
Activation energy $\left(E_{a}\right)$ calculation using Eq. 8 is carried out by plotting $\ln \mathrm{k}$ and $1000 / T$, resulting in two slopes -1.6 and -6.34 which correspond to lower temperatures (30$50{ }^{\circ} \mathrm{C}$ ) and higher temperature $\left(50-80{ }^{\circ} \mathrm{C}\right)$, respectively. Based on the plot of In $k$ and $1000 / T$, energy activation obtained is 13.11 $\mathrm{kJ} / \mathrm{mol}$ for lower temperature leaching and $52.68 \mathrm{~kJ} / \mathrm{mol}$ for higher temperature leaching. The values indicated that at a lower temperature, physical interaction is more prominent $(<40 \mathrm{~kJ} / \mathrm{mol})$, while at a higher temperature, chemical interaction is more dominant (Cantu et al., 2014).

The order of each parameter, especially tannic acid and acetic acid concentration, had to be determined by plotting In $k$ (rate constant) with In [concentration] to develop the rate equation (Fig. 7). Based on the slope value obtained, the order for tannic acid and acetic acid concentration are 1.28 and 0.73 , respectively. Lower reaction order of acetic acid as reactant confirms limited function as acid conditioner during leaching. This value is considered higher compared to other acid modifiers such as sulfuric acid (0.36) in $\mathrm{Mn}$ leaching using bagasse pith (Gan et al., 2018) and sulfuric acid (0.1) in Mn leaching using $\mathrm{SO}_{2}$ gas as a reductant (Sun et al., 2020). Hence the empirical rate equation for lower temperature (Eq. 9, DIT) and higher temperature (Eq. 10, SPM) are as follows:

$$
\begin{aligned}
& \frac{1}{3} \ln (1-x)-\left[1-(1-x)^{-1 / 3}\right] \\
& =\left(8.084 .10^{-5}[T A]^{1.28}[A C]^{0.73} e^{-13110 / R T}\right) t \\
& 1-\frac{2}{3} x-(1-x)^{2 / 3} \\
& =\left(1209.85[T A]^{1.28}[A C]^{0.73} e^{-52681 / R T) t}\right.
\end{aligned}
$$

where $x, T A, A c, R, T$ and $t$ are dissolved $\mathrm{Mn}$ fraction, tannic acid concentration $(\mathrm{g} / \mathrm{L})$, 
acetic acid concentration (molar), gas constant, leaching temperature and leaching time, respectively.
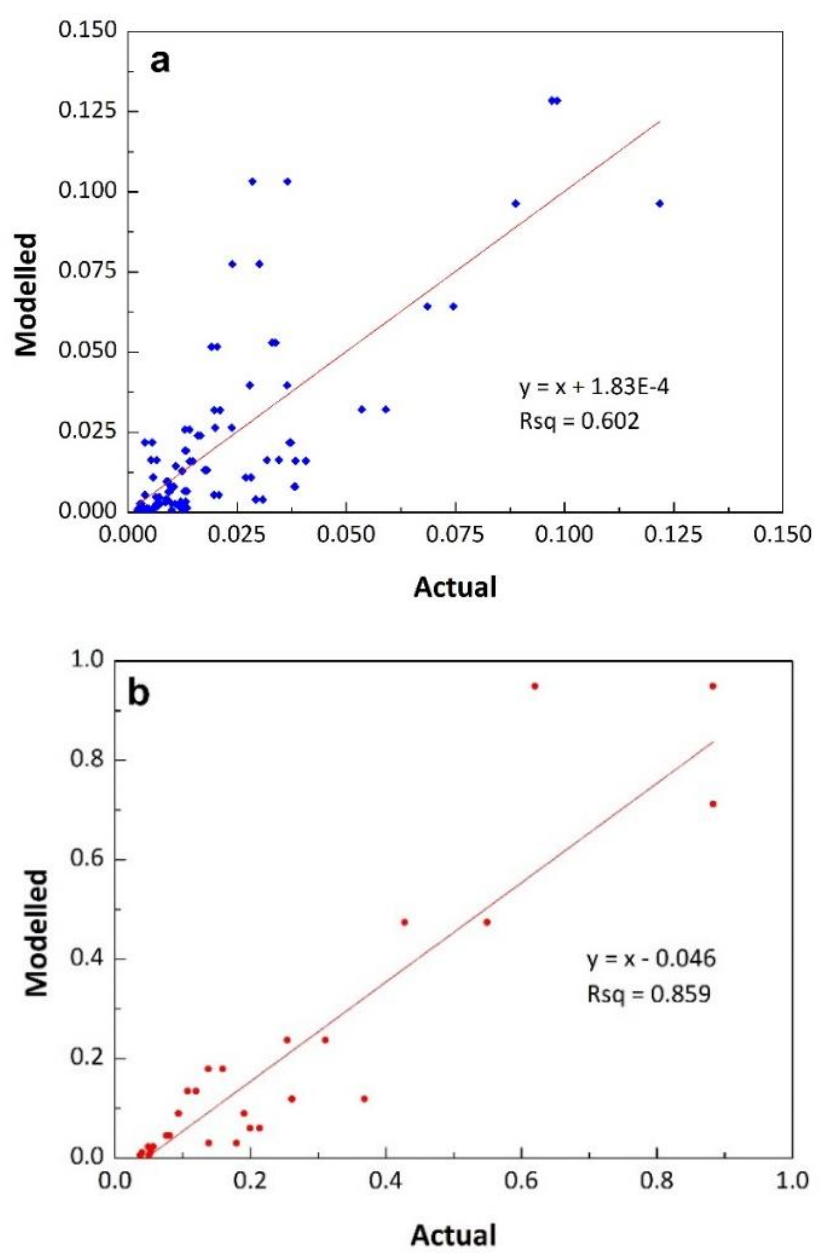

Fig. 8. Plot between Actual Value and Value Obtained from Model in Eq. 9 for Lower Temperature (a) And Eq. 10 for Higher Temperature (b).

Fig. 8 shows the plot between actual (experimental) and calculated data to test the validity of both empirical rate equations, which results in $R^{2} 0.602$ and 0.859 for low and high temperatures, respectively. Based on statistical analysis using a t-test to the coefficient correlation, there was a significant linear relationship between modelled and actual values for lower and higher temperatures.

\section{CONCLUSIONS}

The reductive leaching of psilomelane by tannic-acetic acid was investigated in terms of kinetic parameters. Tannic acid concentration, acetic acid concentration, and temperature positively affect manganese leaching efficiency while increasing particle size and pulp density suppress the leaching efficiency. Fitting experimental data using shrinking core, shrinking particle, and diffusion-interface transfer model indicated that two leaching mechanisms appear during leaching based on temperature. At room temperature leaching $\left(30^{\circ} \mathrm{C}\right)$, the leaching efficiency is affected by reaction rate among reactants and their concentration in bulk volume based on fitting results using diffusion-transfer interface model. In contrast, the shrinking particle model fitted the data best at a higher temperature. It indicated that the diffusion process is more prominent at higher temperatures due to higher energy input encouraging particle movement (diffusion) into the inner particle layer. Calculated activation energy using the Arrhenius equation at two different temperatures yields 13.1 and $52.7 \mathrm{~kJ} / \mathrm{mol}$ for lower and higher temperatures, respectively. Semi-empirical models are proposed for each temperature range. The effect of reactants on leaching efficiency is demonstrated by their order based on the plot of apparent rate constant and concentration, which are 1.28 and 0.73 for tannic acid and acetic acid, respectively.

\section{REFERENCES}

1. Al-Anber, M.A., Al-Momani, I.F., Zaitoun, M.A., Al-Qaisi, W. (2020). "Inorganic silica gel functionalized tris(2aminoethyl)amine moiety for capturing 
198 A Kinetic Study of Manganese Leaching from Low-Grade Psilomelane Ore by Acetic-tannic Acid Lixiviant

aqueous uranium $(\mathrm{VI})$ ion", J. Radioanal.

Nucl. Chem., 325, 605-623.

doi:10.1007/s10967-020-07270-x

2. Andini, D.T., Prasetyo, E., Qudus, H.I., (2020, November 19-20). "Oxidative fusion and alkaline leaching for manganese extraction from low grade silicate ore", 4th International Seminar on Metallurgy and Materials (ISMM2020), Tangerang Selatan, Indonesia.

https://doi.org/10.1063/5.0060058

3. Azizi, D., Shafaei, S.Z., Noaparast, M., Abdollahi, H. (2012). "Modeling and optimization of low-grade $\mathrm{Mn}$ bearing ore leaching using response surface methodology and central composite rotatable design", Trans. Nonferrous Met. Soc. China, 22(9), 2295-2305.

doi:10.1016/S1003-6326(11)61463-5

4. Biswas, R.K., Karmakar, A.K., Kumar, S.L., (2016). "Recovery of manganese and zinc from spent $\mathrm{Zn}-\mathrm{C}$ cell powder: Experimental design of leaching by sulfuric acid solution containing glucose". Waste Manag., 51, 174-181. doi:10.1016/j.wasman.2015.11.002

5. Buzatu, M., Săceanu, S., Petrescu, M.l., Ghica, G. V., Buzatu, T. (2014). "Recovery of zinc and manganese from spent batteries by reductive leaching in acidic media". J. Power Sources, 247, 612-617. doi:10.1016/j.jpowsour.2013.09.001

6. Cantu, Y., Remes, A., Reyna, A., Martinez, D., Villarreal, J., Ramos, H., Trevino, S., Tamez, C., Martinez, A., Eubanks, T., Parsons, J.G. (2014). "Thermodynamics, kinetics, and activation energy studies of the sorption of chromium(III) and chromium(VI) to a $\mathrm{Mn3O}$ nanomaterial". Chem. Eng. J., 254, 374383.

doi:10.1016/j.cej.2014.05.110
7. Corathers, L.A. (2019). Manganese - 2015 [Advance Release], US Geological Survey.

8. Deng, L., Qu, B., Su, S. jun, Ding, S. Ian, Sun, W. yi, (2019). "Separation of Manganese from Iron in the $\mathrm{SO} 2$ Reductive Leaching Iron-Rich Pyrolusite Ore: Leaching Mechanism and Kinetics", Arab. J. Sci. Eng., 44, 5335-5344. doi:10.1007/s13369-018-3587-2

9. Dickinson, C.F., Heal, G.R., (1999). "Solidliquid diffusion controlled rate equations". Thermochim. Acta, 340-341, 89-103. doi:10.1016/s0040-6031(99)00256-7

10. El Hazek, M.N., Gabr, A.A. (2016). "Dissolution of Manganese from Polymetallic Material Using SulfuricOxalic Acid Medium". Am. J. Anal. Chem., 7(5), 469-477. doi:10.4236/ajac.2016.75044

11. Gan, J., Cui, J., Li, X., Muhammad, Y., Wang, Y., Su, H. (2018). "Kinetics of manganese leaching from an iron-rich manganese dioxide ore with bagasse pith as a reductant". New J. Chem., 42, 20144-20151. doi:10.1039/c8nj03875a

12. Guo, H., Yu, H. zhao, Zhou, A. an, Lu, M. hua, Wang, Q., Kuang, G., Wang, H. Dong. (2019). "Kinetics of leaching lithium from $\alpha$-spodumene in enhanced acid treatment using $\mathrm{HF} / \mathrm{H} 2 \mathrm{SO} 4$ as medium". Trans. Nonferrous Met. Soc. China, 29(2), 407-415. doi:10.1016/S1003-6326(19)64950-2

13. Levenspiel, O. (1999). Chemical reaction engineering. John Wiley \& Sons, USA.

14. Lin, Q. quan, Gu, G. hua, Wang, H., Zhu, R. feng, Liu, Y. cai, Fu, J. Gang. (2016). "Preparation of manganese sulfate from low-grade manganese carbonate ores by sulfuric acid leaching". Int. J. Miner. Metall. Mater., 23(5), 491-500. 
doi:10.1007/s12613-016-1260-x

15. Lu, Y., Ma, H., Huang, R., Yuan, A., Huang, Z., Zhou, Z. (2015). "Reductive Leaching of Low-Grade Pyrolusite with Formic Acid". Metall. Mater. Trans. B Process Metall. Mater. Process. Sci., 46, 17091715.

doi:10.1007/s11663-015-0380-4

16. Momade, F.W.Y., Momade, Z.G. (1999). "Reductive leaching of manganese oxide ore in aqueous methanol-sulphuric acid medium". Hydrometallurgy, 51(1), 103113.

doi:10.1016/s0304-386x(98)00077-2

17. Moosakazemi, F., Ghassa, S., Mohammadi, M.R.T. (2019). "Environmentally friendly hydrometallurgical recovery of tin and lead from waste printed circuit boards: Thermodynamic and kinetics studies". J. Clean. Prod., 228, 185-196.

doi:10.1016/j.jclepro.2019.04.024

18. Pagnanelli, F., Furlani, G., Valentini, P., Vegliò, F., Toro, L. (2004). "Leaching of low-grade manganese ores by using nitric acid and glucose: Optimization of the operating conditions". Hydrometallurgy, 75(1-4), 157-167. doi:10.1016/j.hydromet.2004.07.007

19. Prasetyo, E., Anderson, C., Nurjaman, F., Al Muttaqii, M., Handoko, A.S., Bahfie, F., Mufakhir, F.R., (2020). "Monosodium glutamate as selective lixiviant for alkaline leaching of zinc and copper from electric arc furnace dust". Metals, 10(5), 644-657.

doi:10.3390/met10050644

20. Prasetyo, E., Purwaningsih, E., Astuti, W. (2019). "Selective-Reductive Leaching of Manganese from Low-Grade Manganese Ore Using Tannic Acid as Reductant". Mining, Metall. Explor. 36(5), 1003-1012. doi:10.1007/s42461-019-00115-6
21. Sinha, M.K., Purcell, W., Van Der Westhuizen, W.A. (2020). "Recovery of manganese from ferruginous manganese ore using ascorbic acid as reducing agent". Miner. Eng., 154, 106406.

doi:10.1016/j.mineng.2020.106406

22. Sun, D., Xin, G., Yao, L., Yang, L., Jiang, X., Jiang, W. (2020). "Manganese leaching in high concentration flue gas desulfurization process with semioxidized manganese ore". Chinese J. Chem. Eng., 28(2), 571-578.

doi:10.1016/j.cjche.2019.09.006

23. Sun, Y., Fu, G., Jiang, L. (2018). "Reductive leaching of low-grade manganese oxide ores using pretreated straw as reductant". Process. Extr. Metall. Trans. Inst. Min. Metall., doi:10.1080/25726641.2018.1505210

24. Trojanowicz, M., Bojanowska-Czajka, A., Bartosiewicz, I., Kulisa, K. (2018). "Advanced Oxidation/Reduction Processes treatment for aqueous perfluorooctanoate (PFOA) and perfluorooctanesulfonate (PFOS) - A review of recent advances". Chem. Eng. J. 336, 170-199.

doi:10.1016/j.cej.2017.10.153

25. Xiong, S., Li, X., Liu, P., Hao, S., Hao, F., Yin, Z., Liu, J. (2018). "Recovery of manganese from low-grade pyrolusite ore by reductively acid leaching process using lignin as a low cost reductant". Miner. Eng., 125, 126-132.

doi:10.1016/j.mineng.2018.06.003

26. Xue, J., Zhong, H., Wang, S., Li, C., Li, J., $\mathrm{Wu}$, F. (2016). "Kinetics of reduction leaching of manganese dioxide ore with Phytolacca americana in sulfuric acid solution Kinetics of reduction leaching of manganese dioxide ore". J. Saudi Chem. Soc., 20(4), 437-442. 
200 A Kinetic Study of Manganese Leaching from Low-Grade Psilomelane Ore by Acetic-tannic Acid Lixiviant

doi:10.1016/j.jscs.2014.09.011

27. Zhang, Y. bo, Zhao, Y., You, Z. xiong, Duan, D. xian, Li, G. hui, Jiang, T. (2015).

"Manganese extraction from high-ironcontent manganese oxide ores by selective reduction roasting-acid leaching process using black charcoal as reductant". J. Cent. South Univ., 22, 25152520. doi:10.1007/s11771-015-2780-7

28. Zheng, F., Zhu, H., Luo, T., Wang, H., Hou, H. (2020). "Pure water leaching soluble manganese from electrolytic manganese residue: Leaching kinetics model analysis and characterization". J. Environ. Chem. Eng., 8(4), 103916. doi:10.1016/j.jece.2020.10391 